\title{
Biocomposites Based on Chitosan and Carnauba Straw Powder
}

\author{
Márcia Rodrigues Pereira, Jéssica Souza Marques, José Luís Cardozo Fonseca \\ Chemistry Institute - IQ, Federal University of Rio Grande do Norte - UFRN
}

\begin{abstract}
In this study carnauba straw powder was submitted to chemical treatments using alkali $(\mathrm{NaOH})$ or hexane, in order to increase its hydrophilicity and to investigate its potential use for the development of a biodegradable composite. Biocomposites were prepared in solution, using carnauba straw powder and chitosan as matrix, with powder contents of 10 and $50 \mathrm{wt} \%$. Both, straw powder and biocomposites, were characterized by chemical composition analysis, FTIR, TGA, DSC and SEM. According to the results, the chemical treatment using $\mathrm{NaOH}$ was efficient in removing the soluble components of the powder and cleaning its surface. DSC analyses demonstrated that the addition of high powder loadings does not reduce the thermal stability of the composite. The elastic modulus of the biocomposites obtained with $10 \mathrm{wt} \%$ of untreated carnauba powder remained unaltered, decreasing for a filler content of $50 \mathrm{wt} \%$. The effect of $\mathrm{NaOH}$ chemical treatment was more evident for the composite with $50 \mathrm{wt} \%$ of powder.
\end{abstract}

Keywords: Biocomposites, carnauba straw powder, chitosan, chemical treatment.

\section{Introduction}

The species copernicia prunifera (Miller.) H.E.Moore, 1963, widely known in Brazil as carnaubeira, is a palm tree often occurring in the northeast of the country. The study of this lignocellulosic material has the potential to generate a whole new set of applications, such as in the preparation of biocomposites. In fact, the crescent interest in the use of lignocellulosic materials in biocomposites has been driven by their low specific weight, that provides lighter materials, with higher strength and rigidity ${ }^{[1,2]}$, as well as lower equipment damage, when compared to fiberglass reinforced composites $^{[3]}$. Besides, biocomposites are completely degraded in soil or by composting processes ${ }^{[4,5]}$.

An increase in environmental awareness has led scientists to produce biodegradable composites that consist of biopolymers as the matrices and natural fillers as reinforcement ${ }^{[6]}$. Chitosan, a versatile biopolymer of interesting structure and remarkable properties such as biocompatibility, biodegradability, availability from stable renewable sources, low immunogenicity and biological activity as well as the ability to form films and membranes ${ }^{[7]}$, stands out as a potential choice for these systems. This macromolecule consists of a linear copolymer composed by glucosamine and $\mathrm{N}$-acetylglucosamine units, obtained by deacetylation of chitin, a natural polymer found in the exoskeleton of arthropods and fungi ${ }^{[7,8]}$. Its physico-chemical characteristics give rise to applications encompassing health care (dietary fiber, drug release, tissue engineering matrices), water treatment (membrane filter), food packaging (edible coating), agriculture, among others ${ }^{[9]}$.

There is plenty of work on reinforcement of polymers using natural fillers without changing their inherent properties $^{[10-17]}$. Although the use of lignocellulosic materials in composites has widely been reported in the literature, to our best knowledge no work using materials derived from carnauba in the preparation of composites with chitosan has been related. Besides, both chitosan and carnauba are plentiful, relatively cheap, renewable, biodegradable and relatively non-toxic and sustainable products: the association of these materials would result in the possibility of a new range of biocomposites, with new technological applications such as automobilist area, package industry and artificial wood. Therefore, the aim of this work is to evaluate the influence of carnauba straw powder incorporation (chemically treated or not) on the reinforcing of a chitosan matrix.

\section{Experimental}

\section{Carnauba straw powder preparation}

Carnauba straw was kindly provided by a handcraft community located in the state of Rio Grande do Norte, in the northeastern region of Brazil. The material was washed with neutral detergent solution and dried in oven at $60{ }^{\circ} \mathrm{C}$, for $6 \mathrm{~h}$. The dry material was ground to 20-30 Mesh, using a knife-grinding machine (MA340/4, Brazil). The resultant powder was separated into different granulometries using granulometric sieves from 20 to $400 \mathrm{Mesh} / \mathrm{Tyler}$, for 15 minutes and $5 \mathrm{rpm}$. Carnauba straw powder composition was determined according to the methodology reported by Goering and van Soest ${ }^{[18]}$, yielding the following values, in percentage: humidity (7.8\%); ash (3.8\%); hemicellulose (29\%); lignin (14\%); cellulose (41\%).

\section{Carnauba straw powder treatments}

After separation, it was observed that about $50 \%$ of material was retained at 100 and 150 Mesh sieves. Therefore these samples were chosen to be submitted to chemical treatments. The samples were submitted to two different chemical treatments, one using sodium

Corresponding author: Márcia Rodrigues Pereira, Instituto de Química - IQ, Universidade Federal do Rio Grande do Norte - UFRN, Av. Senador Salgado Filho, 3000, Lagoa Nova, Campus Universitário, CEP 59078-970, Natal, RN, Brasil, e-mail: mrpereira.ufrn@gmail.com 
hydroxide (P.A., Cromoline Química Fina Ltd, Brazil) and the other, hexane (P.A., Cromoline Química Fina Ltd, Brazil). The alkaline treatment was carried out by immersing the powder in an aqueous $0.1 \mathrm{~N} \mathrm{NaOH}$ solution, under constant stirring, at $40{ }^{\circ} \mathrm{C}$, for $30 \mathrm{~min}$. Subsequently, the powder was washed several times with distilled water, until neutral $\mathrm{pH}$, and dried in oven at $50{ }^{\circ} \mathrm{C}$ for $24 \mathrm{~h}$.

The treatment with hexane was carried out in a Soxhlet extractor, at $65^{\circ} \mathrm{C}$, for $6 \mathrm{~h}$. The resultant powder was washed several times in distilled water for the removal of water-soluble substances and dried in oven at $50{ }^{\circ} \mathrm{C}$ for $24 \mathrm{~h}$.

\section{Composites preparation}

Chitosan powder was purchased from Polymar Ltd, Brazil with a viscometric average molar mass, $\left(\mathrm{M}_{\mathrm{v}}\right)$ of $1.9 \times 10^{5}$, and a deacetylation degree of $85 \pm 5^{[19]}$. Acetic acid (99.5\%, Cromato Produtos Químicos Ltd, Brazil) was used as received.

Chitosan solution was prepared by dissolving a given mass of chitosan in a $2 \%(\mathrm{v} / \mathrm{v})$ acetic acid solution at room temperature, in order to obtain a $2 \%(\mathrm{v} / \mathrm{v})$ solution. Afterwards, the solution was filtered using a Millex Millipore with an average pore diameter of $0.41 \mu \mathrm{m}$. Carnauba powder was then added to the solution at concentrations of 10 and $50 \mathrm{wt} \%$. Following, $100 \mathrm{ml}$ of the mixture was casted on a glass plate with dimensions of $18.0 \times 18.0 \mathrm{~cm}$. The resultant film was oven-dried overnight at $50{ }^{\circ} \mathrm{C}$. Once the film was dried, it was then neutralized using a $0.5 \mathrm{M} \mathrm{NaOH}$ solution and further dried at room temperature. The films were stored in desiccators until further use. Composites were named CSUNT10 (10 wt $\%$ of untreated carnauba powder), CSHEX10 (10 wt $\%$ of carnauba powder treated with hexane), and CSNaOH10 (10\% of carnauba treated with $\mathrm{NaOH}$ ). Composites with $50 \mathrm{wt} \%$ of carnauba powder received similar names, replacing the 10 by 50 , e.g., CSUNT50.

\section{Powder and composites characterization}

The main functional chemical groups in powdered samples were characterized by infrared spectroscopy, using an FTIR spectrometer (Nexus 470, Thermo Nicolet, USA), operating in the wavenumber interval of 4000-400 $\mathrm{cm}^{-1}$ in transmission mode, with a resolution of $4 \mathrm{~cm}^{-1}$ and 32 scans. Carnauba straw powder samples were prepared in the form of pressed $\mathrm{KBr}$ pellets.

Thermogravimetric analyses (TGA) were carried out in a Shimadzu equipment (model TGA-50, Japan) to measure the thermal stability of the powder and composites. All samples were scanned under a nitrogen flow rate of $50 \mathrm{~mL} / \mathrm{min}$, heating rate of $10^{\circ} \mathrm{C} / \mathrm{min}$, and temperature ranging from room temperature to $600{ }^{\circ} \mathrm{C}$.

Differential scanning calorimetry (DSC) was also performed in a Shimadzu equipment (model DSC 50, Japan), under a nitrogen flow rate of $20 \mathrm{~mL} / \mathrm{min}$, heating rate of $10{ }^{\circ} \mathrm{C} / \mathrm{min}$, and temperature range from room temperature to $450{ }^{\circ} \mathrm{C}$.

The morphologies of the powders, before and after chemical treatments as well as the fracture cross section of the final biocomposites were examined using a Philips electronic scanning microscope (model XL-30, USA) equipped with a tungsten filament, operating at $20 \mathrm{kV}$, in SE (secondary electrons) mode. After the deposition of gold on the particle surfaces, micrographs with magnitude of 500, 1000x and 2000x were taken.

Tensile proprieties of the composites with 10 and $50 \mathrm{wt} \%$ of the carnauba straw powder were performed using a Dyna View (Oswaldo Filizola Ltd., Brazil) testing machine. Rectangular samples measuring $10 \times 1.0 \times 0.01 \mathrm{~cm}$ were tested at a crosshead displacement of $10 \mathrm{~mm} / \mathrm{min}$. Seven samples were tested for each composition and the average values were calculated.

\section{Results and Discussion}

\section{Carnauba powder characterization}

Granulometric results indicated that most of the powder was retained on the 100 mesh $(25 \%)$ and 150 mesh $(27 \%)$ sieves. Therefore, the samples used in this work are composed by the powder retained in the 100 and 150 mesh sieves, having an average particle size between 0.15 and $0.10 \mathrm{~mm}$. Comparing the contents of cellulose, hemicellulose, and lignin from the carnauba straw powder with some other natural materials widely used as reinforcement in composite materials (e.g., jute, sisal, and linen) it can be found that carnauba straw powder has a lower cellulose content (40\%, compared to $60-80 \%$ of other vegetable fibers) in detriment of a higher content of hemicellulose $(\sim 30 \%$, compared to $10-20 \%)^{[20]}$. This content combination indicates that one have a soft, high humidity absorber, and biodegradable material.

Infrared spectra of carnauba straw powder, treated and untreated, are displayed in Figure 1. All spectra show absorption bands characteristic of lignocellulosic compounds $^{[21]}$ as previously characterized ${ }^{[22]}$. Alkaline treatment resulted in a higher definition of the $3400 \mathrm{~cm}^{-1}$ absorption, possibly indicating an increase in hydrophilicity. Sanchez et al. ${ }^{[23]}$ have correlated the increase in associated hydroxyl groups to the destruction

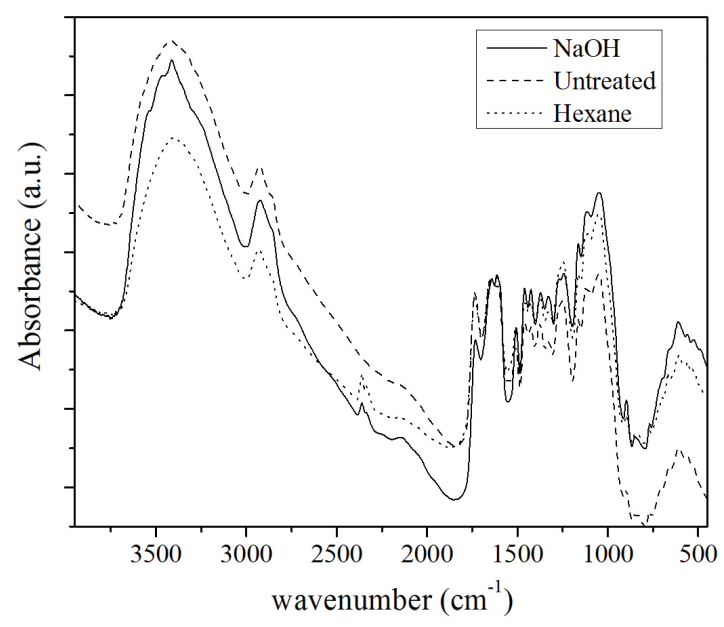

Figure 1. FTIR of untreated carnauba straw powder, treated with $\mathrm{NaOH}$ and with hexane. 
of lignin and hemicellulose/cellulose interactions produced by alkaline treatment. There is also a reduction in the intensity at the absorption band at around $1740 \mathrm{~cm}^{-1}$, corresponding to carbonyl vibration, after alkaline treatment, suggesting a partial removal of soluble components from the powder, i.e., hemicellulose and a small part of lignin. Elimination was only partial probably due to the mild conditions used in this work. The sample treated with hexane did not show any significant change in the infrared spectrum.

Figure 2 presents the three DTG and DSC curves obtained for the untreated powder, powder treated with hexane, and with alkali. The results show that for the untreated powder three events can be identified: a weight loss of about $6 \%$ in the temperature range of 35 to $81{ }^{\circ} \mathrm{C}$, attributed to the loss of water, followed by other of $56 \%$ at $296^{\circ} \mathrm{C}$, and a third one of $\mathrm{ca} .13 \%$, at $497^{\circ} \mathrm{C}$. For the treated powders the weight losses relative to intra- and intermolecular dehydration reactions are virtually the same, although they happen at slightly lower temperatures. The first substantial difference observed is at the first and second degradation events, which occurred as a unique step for the untreated sample and seems to be split into two after chemical treatments. Besides, the weight loss at the second event at $\sim 500{ }^{\circ} \mathrm{C}$ decreases from $13 \%$ on the untreated powder to about $8 \%$ on the chemically treated samples. According to the literature ${ }^{[24,25]}$, thermogravimetric curves of lignocellulosic materials generally present characteristic peaks of two of their main components: hemicellulose and cellulose. In case of the third component, lignin, it has been reported that, due to its complex structure, its degradation occurs very slowly, at a wide temperature range ${ }^{[25]}$. Still according to the literature, the first step of degradation is associated to hemicellulose depolymerization, cellulose degradation occurring at higher temperature rates (compared to hemicellulose) ${ }^{[25]}$. Some authors point out that the peak at $\mathrm{ca} .500{ }^{\circ} \mathrm{C}$ can be attributed to carbonization residue ${ }^{[24]}$. The results confirm the tendency observed from FTIR results: the alkaline treatment partially removed hemicellulose (weight loss decline from $56 \%$ to $28 \%$ ) and with this reduction the event related to cellulose degradation became more evident. There is also a reduction in the third event related to carbonization residue. Finally, the results show that, although hexane treatment is not as effective as the alkaline one, it is also capable of partially removing soluble components (hemicellulose and lignin).

DSC curves for the carnauba powders are shown in Figure 2b. The three thermograms begin with an endothermic peak $\left(26-100{ }^{\circ} \mathrm{C}\right)$, corresponding to the dehydration step. The second peak is exothermic, begins around $220^{\circ} \mathrm{C}$, with maxima at $282{ }^{\circ} \mathrm{C}$ for the untreated powder, $287{ }^{\circ} \mathrm{C}$ for the powder treated with alkali and $285^{\circ} \mathrm{C}$ for the powder treated with hexane. This second peak is clearly related to the degradation of hemicellulose, since it occurs at the same temperature range observed on thermogravimetric analysis. There is also a third peak, with maxima at $341{ }^{\circ} \mathrm{C}$ for the untreated powder, $348^{\circ} \mathrm{C}$ for the powder treated with alkali, and $349{ }^{\circ} \mathrm{C}$ for the powder treated with hexane. This third peak is exothermic for the untreated powder and endothermic for the treated ones. According to the literature ${ }^{[26]}$, one can find in this region an endothermic peak related to the decomposition of cellulose as well as an exothermic peak related to the pyrolysis of lignin. Comparing thermograms of treated and untreated materials one can observe that the endothermic peak of cellulose, located at the same region of the exothermic peak of lignin, is present only for the treated samples. Besides, the endothermic peak is more evident in the powder treated with alkali, indicating, again, the efficiency of this treatment in the removal not only of hemicellulose, but also of lignin.

Figure 3 shows electron micrographs of the surface of the untreated and treated powders studied in this work. The micrographs show a randomly distributed organic material that covers the powder surface. This organic material is probably a residue of wax left after its extraction. It is also possible to observe parenchyma cells at the surface of the powder. Apart from parenchyma cells, some ordered white dots can also be identified (magnified in Figure 3d). These star-like protrusions, named tylose, have already been found in $\operatorname{coir}^{[27]}$ and piassava fibers and have been characterized by EDS as Si rich particles ${ }^{[28]}$. According to the photomicrographs,

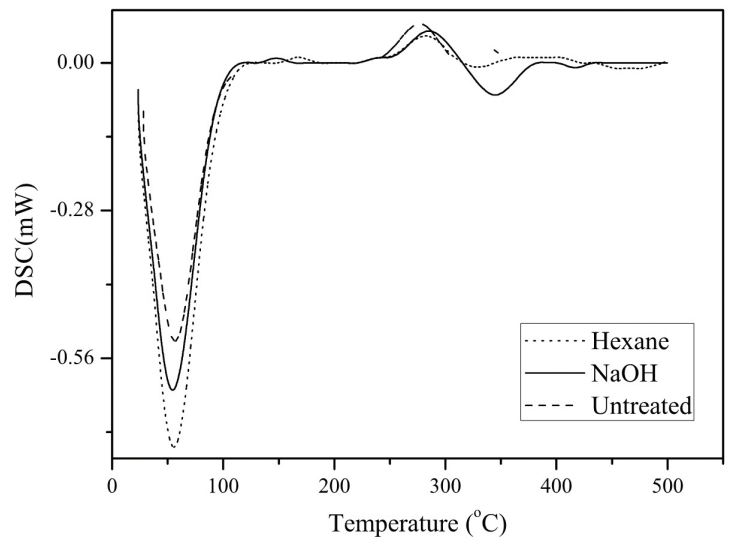

(b)

Figure 2. (a) TG and (b) DSC of untreated carnauba straw powder, treated with $\mathrm{NaOH}$ and with hexane. 


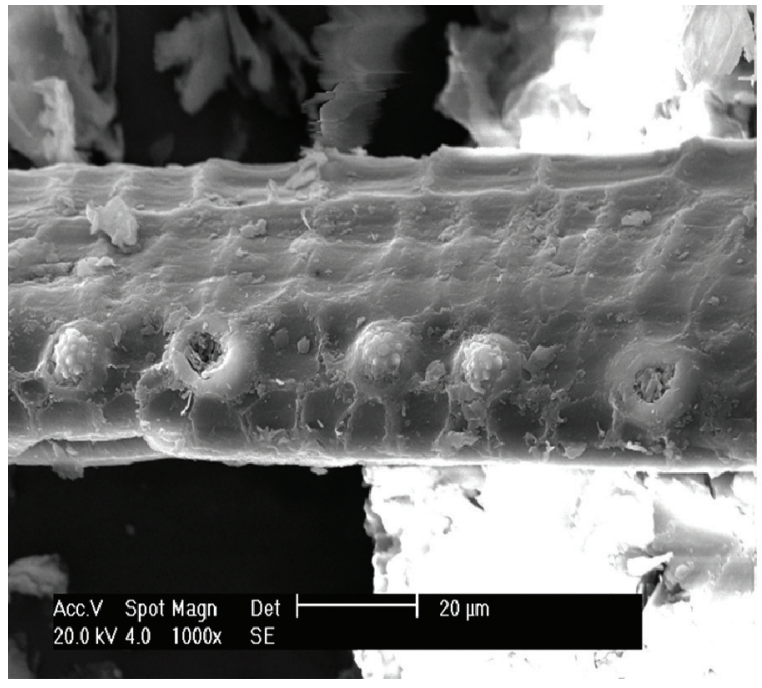

(a)

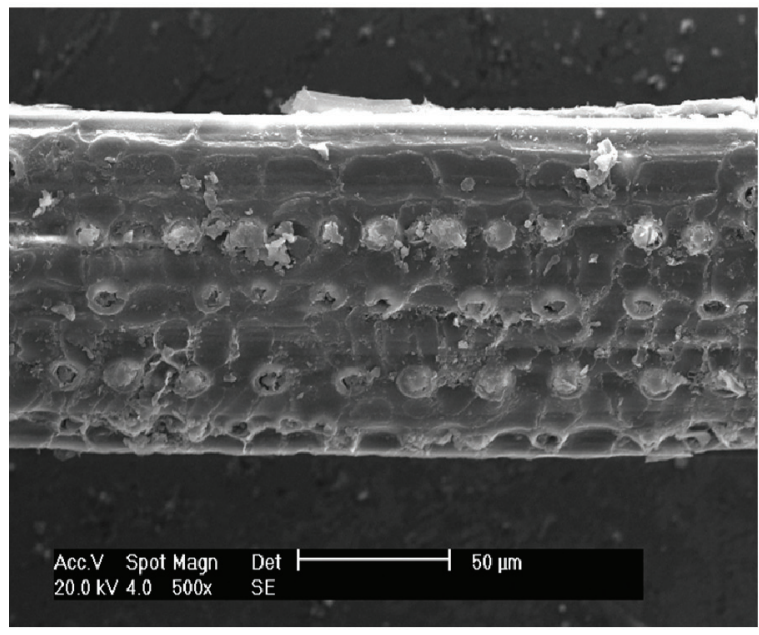

(c)

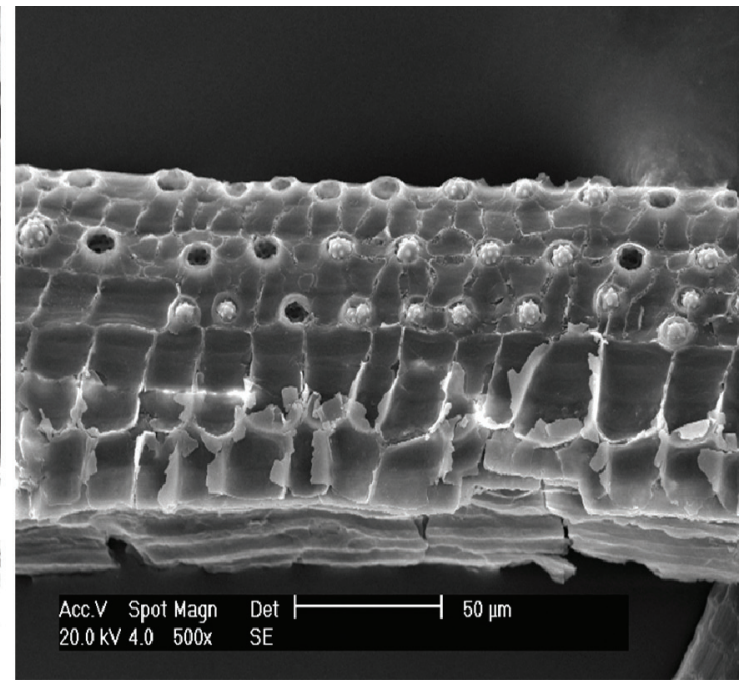

(b)

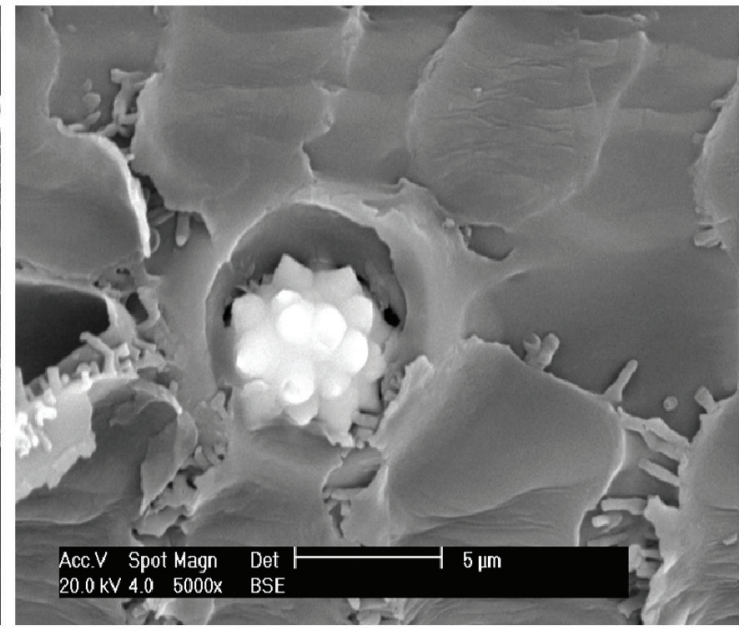

(d)

Figure 3. SEM images of a) untreated sample (1000x), b) treated with $\mathrm{NaOH}(500 \mathrm{x})$, c) treated with hexane (500x) and d) treated with $\mathrm{NaOH}(5000 \mathrm{x})$.

the treatments promote partial removal of the wax layer yielding a rougher and cleaner surface. Also in this case, alkaline treatment seems to be the most effective one.

\section{Composite characterization}

Results from thermogravimetric analysis of untreated carnauba powder-chitosan composites are shown in Figure 4. Untreated powder was chosen because, as it will be showed below, it presented the best performance in terms of mechanical properties. According to the results, the presence of carnauba powder did not cause significant changes either in the amount of water in the composites or on its release temperature. Besides, its is also shown that the second event, which occurs in a single step for pure chitosan, changes to a two stepped degradation profile, with a small shoulder at $\sim 360{ }^{\circ} \mathrm{C}$ that increases as powder content is increased. This peak is probably related to the cellulose component depolymerization, yielding volatile products ${ }^{[24]}$. It is important to point out that although carnauba powder has a degradation temperature lower than the chitosan one, the composites have a degradation temperature similar to pure chitosan, indicating that the powder, even at high loadings, does not reduce the thermal stability of the composites.

\section{Mechanical properties}

The average tensile stress-strain curves of carnauba straw powder/chitosan biocomposites with $10 \%$ and $50 \%$ of carnauba powder (treated and untreated) are outlined in Figure 5 and Table 1. All curves were recorded until the samples were completely fractured. In general, the addition of carnauba powder to chitosan has significantly modified the profile of the stress-strain curve as compared to the pure chitosan film, typically the elastic modulus, strain at break and rupture tension. By comparing the tensile strength results of pure chitosan films (Table 1) with chitosan containing $10 \%$ of carnauba powder, it is observed a decrease in rupture tension and strain at break 
although modulus remained essentially constant. On the other hand, when comparing pure chitosan film tensile strength with the one related to chitosan biocomposite containing $50 \%$ of carnauba powder, it is observed a dramatic decrease of all measured parameters, including elastic modulus. In fact, the literature has shown that a reinforcing effect usually is achieved using very low amounts of particulate fibers (from $1 \%$ to $5 \%$ ) $^{[29,30]}$.

For higher load contents, the decrease in tensile strength is normally attributed to insufficient incorporation of this high filler amount and/or poor interfacial adhesion

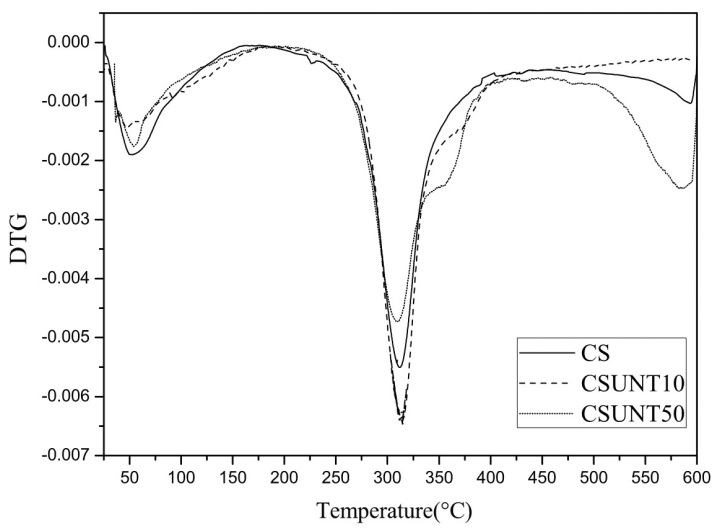

Figure 4. DTG of pure chitosan (CS), with $10 \%$ of untreated carnauba powder (CSUNT10) and with $50 \%$ of untreated carnauba straw powder (CSUNT50).

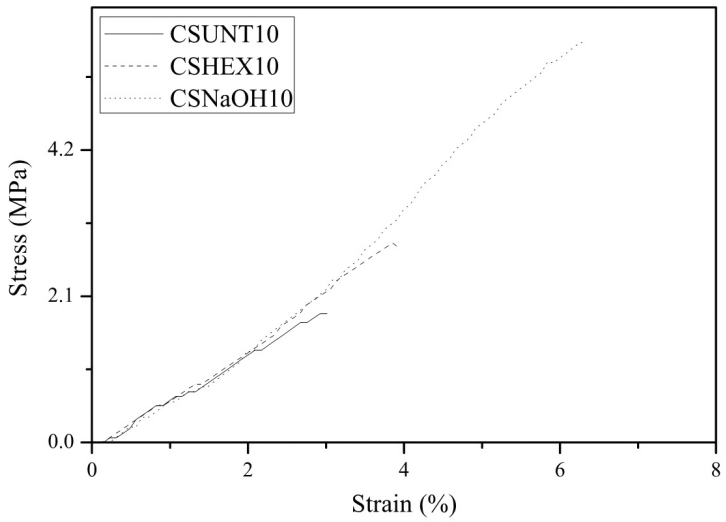

(a) between filler and composite matrix. For the biocomposite containing $10 \%$ of carnauba powder, biocomposites with untreated powder yielded the best results. On the other hand, for the biocomposite containing $50 \%$ of carnauba powder, despite the decrease in tensile strength, indicating an insufficient incorporation of filler, chemically treated powders seemed to positively contribute to composite final mechanical properties. Literature has cited several and sometimes contradicting effects of chemical treatments on the tensile properties of lignocellulosic materials ${ }^{[29,30]}$. These effects are not solely a function of experimental conditions (time, temperature and concentration) but also of material chemical composition, its origin and growth condition. Concerning alkali treatment, the improvement in strength is usually related to surface impurity removal (supported here by SEM results), in addition to the partial dissolution of hemicellulose (evidenced by infrared spectra). Conversely, the reduction in strength caused by alkaline treatment can be attributed to the dissolution of alkali soluble components, creating voids in the powder structure, which results in sharp drop in tensile properties.

Figure 6 shows cross section electronic micrographs of biocomposites with $10 \%$ of carnauba powder untreated and treated with $\mathrm{NaOH}$ and hexane with magnification of 2000x. From the micrographs it is possible to notice that the composite using untreated powder presents better powder/matrix adhesion indicating that the chemical

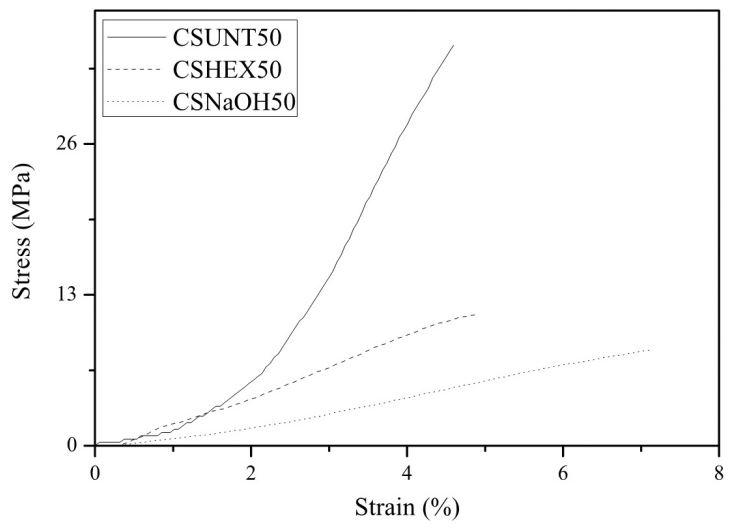

(b)

Figure 5. Stress x strain curves of carnauba straw powder filled chitosan biocomposites with (a) $10 \%$ and (b) $50 \%$ of straw powder with different chemical treatments.

Table 1. Tensile properties of carnauba straw powder filled chitosan biocomposites with $10 \%$ and $50 \%$ of carnauba straw powder with different chemical treatments.

\begin{tabular}{lccc}
\hline Specimen & $\begin{array}{c}\text { Rupture Tension } \\
(\text { MPa) }\end{array}$ & $\begin{array}{c}\text { Elastic Modulus } \\
(\text { MPa })\end{array}$ & $\begin{array}{c}\text { Elongation } \\
(\%)\end{array}$ \\
\hline CS & $65 \pm 7$ & $1100 \pm 100$ & $35 \pm 4$ \\
CSUNT10 & $35 \pm 5$ & $1048 \pm 111$ & $4 \pm 1$ \\
CSHEX10 & $11 \pm 2$ & $272 \pm 67$ & $5 \pm 1$ \\
CSNaOH10 & $8 \pm 2$ & $141 \pm 99$ & $7 \pm 2$ \\
CSUNT50 & $2 \pm 1$ & $79 \pm 46$ & $3 \pm 1$ \\
CSHEX50 & $3 \pm 2$ & $76 \pm 23$ & $4 \pm 2$ \\
CSNaOH50 & $6 \pm 1$ & $87 \pm 29$ & $6 \pm 2$ \\
\hline
\end{tabular}




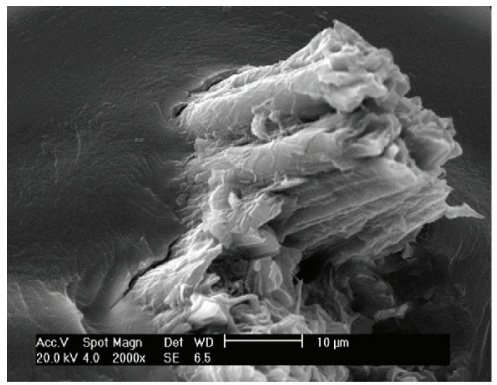

(a)

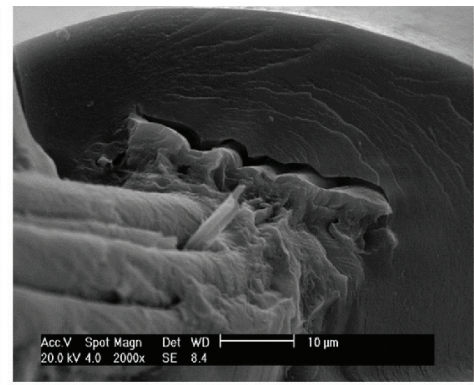

(b)

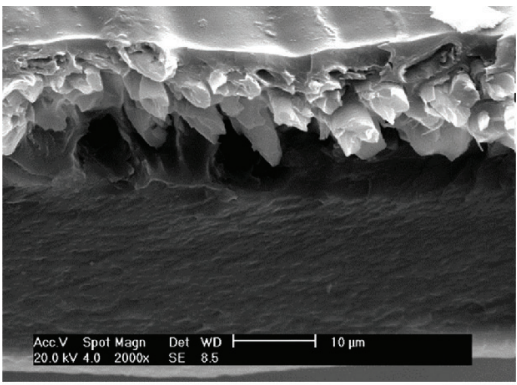

(c)

Figure 6. SEM images of a) composite with untreated carnauba powder CSUNT10, b) treated with $\mathrm{NaOH} \mathrm{CSNaOH10} \mathrm{and,} \mathrm{c)} \mathrm{treated}$ with hexane CSHEX10.

treatments were not effective in increase it. These results corroborates the ones obtained by mechanical tests and confirm the voids generated by chemical treatments decreases the powder/matrix contact, which results in a decreases in tensile properties.

\section{Conclusions}

To the best of our knowledge, an investigation of the chemical composition, thermal stability and tensile properties of carnauba straw's powder and in biocomposites with chitosan is firstly reported. The chemical analysis showed that carnauba straw's powder had lower cellulose content $(40 \%)$ in detriment of a higher hemicellulose one (29\%), compared with other lignocellulosic materials. By FTIR it was possible to conclude that treatment with alkali, although more effective than the one with hexane, removed hemicellulose and lignin only partially and therefore more severe experimental conditions are necessary for a complete removal. Hemicellulose contributed the most to the mass loss rate at temperatures below $300{ }^{\circ} \mathrm{C}$ and cellulose was dominant for the mass loss at temperatures above $300{ }^{\circ} \mathrm{C}$. Lignin contributed the least to the mass loss, and the most to the residues. SEM results allowed us to conclude that the chemical treatment removed organic material existent at the powder surface, alkali treatment being the most effective. From biocomposite's thermograms it was possible to observe that although carnauba powder presented a lower degradation temperature than chitosan, its presence in the biocomposite did not reduce the thermal stability of the biocomposite. From mechanical tests it was possible to conclude that the composition with $10 \%$ of untreated carnauba powder was the best one in terms of biocomposite final mechanical properties. Carnauba straw powder reinforced chitosan biodegradable composite may prove as an alternative to pure chitosan film with cost reduction and similar elastic modulus.

\section{Acknowledgments}

The authors would like to thank Coordenação de Aperfeiçoamento de Pessoal de Nível Superior (Capes) for J.S. Marques MSc. fellowship.

\section{References}

1. Marinelli, A. L.; Monteiro, M. R.; Ambrosio, J. D.; Branciforti, M. C.; Kobayashi, M. \& Nobre, A. D. - Polímeros, 18, p.92 (2008). http://dx.doi.org/10.1590/ S0104-14282008000200005

2. Corradini, E.; Agnelli, J. A. M.; Morais, L. C. de \& Mattoso, L. H. C. - Polímeros, 18, p.353 (2008).

3. Akil, H. M.; Omar, M. F.; Mazuki, A. A. M.; Safiee, S.; Ishak, Z. A. M. \& Abu-Bakar, A. - Mater. Design, 32, p.4107 (2011). http://dx.doi.org/10.1016/j.matdes.2011.04.008

4. Bledzki, A. K. \& Gassan, J. - Prog. Polym. Sci., 24, p.221 (1999). http://dx.doi.org/10.1016/S0079-6700(98)00018-5

5. Bledzki, A. K.; Gassan, J. \& Theis, S. - Mech. Compos. Mat., 34, p.563 (1998). http://dx.doi.org/10.1007/ BF02254666

6. Mohanty, A. K.; Misra, M. \& Hinrichsen, G. - Macromol. Mater. Eng., 276, p.1 (2000). http://dx.doi.org/10.1002/ (S ICI) 1439-2054(20000301)276:1<1: : A ID MAME1>3.0.CO;2-W

7. Ferguson, A. N. \& O’Neill, A. G. - "Focus on chitosan research", Nova Science Publishers, New York (2011).

8. Goosen, M. F. A. - "Applications of Chitin and Chitosan", Technomic Pub., Lancaster (1997).

9. Argüelles-Monal, W. - "Natural and synthetic polymers: challenges and perspectives", in: 7th Latin-American Symposium on Polymers, 5th Ibero-American Congress on Polymers, 1st Ibero-American Symposium on Chitin and Chitosan, Havana, Cuba, nov. (2000).

10. Samal, S. K.; Mohanty, S. \& Nayak, S. K. - J. Reinf. Plast. Comp., 28, p.2729 (2009). http://dx.doi. org/10.1177/0731684408093451

11. Threepopnatkul, P.; Kaerkitcha, N. \& Athipongarporn, N. - Compos. Part B-Eng., 40, p.628 (2009). http://dx.doi. org/10.1016/j.compositesb.2009.04.008

12. Bismarck, A.; Mohanty, A. K.; Aranberri-Askargorta, I.; Czapla, S.; Misra, M.; Hinrichsen, G. \& Springer, J. - Green Chem., 3, p.100 (2001). http://dx.doi.org/10.1039/b100365h

13. Bledzki, A. K. \& Faruk, O. - Compos. Sci. Technol., 64, p.693 (2004). http://dx.doi.org/10.1016/S0266-3538(03)00291-4

14. Brahmakumar, M.; Pavithran, C. \& Pillai, R. M. - Compos. Sci. Technol., 65, p.563 (2005). http://dx.doi.org/10.1016/j. compscitech.2004.09.020 
15. Lopattananon, N.; Payae, Y. \& Seadan, M. - J. App. Polym. Sci., 110, p.433 (2008). http://dx.doi.org/10.1002/ app.28496

16. Luz, S. M.; Goncalves, A. R.; Del'arco, A. P. \& Ferrão, P. M. C. - Compos. Interface, 15, p.841 (2008). http://dx.doi. org/10.1163/156855408786778366

17. Tomczak, F.; Satyanarayana, K. G. \& Demetrio Sydenstricker, T. H. - Compos. Part A-Appl. S., 38, p.2227 (2007).

18. Goering, H. K.; Gordon, C. H.; Hemken, R. W.; Vansoest, P. J. \& Smith, L. W. - J. Dairy Sci., 53, p.676 (1970).

19. Santos, Z. M. dos; Caroni, A. L. P. F.; Pereira, M. R.; Silva, D. R. da \& Fonseca, J. L. C. - Carbohyd. Res., 344, p.2591 (2009). PMid:19853840. http://dx.doi.org/10.1016/j. carres.2009.08.030

20. Kabir, M. M.; Wang, H.; Lau, K. T. \& Cardona, F. - Compos. Part B-Eng., 43, p.2883 (2012). http://dx.doi.org/10.1016/j. compositesb.2012.04.053

21. Sgriccia, N.; Hawley, M. C. \& Misra, M. - Compos. Part A-Appl. S., 39, p.1632 (2008).

22. Fernandes, J. E.; Dantas, T. N. D.; Fonseca, J. L. C. \& Pereira, M. R. - J. App. Polym. Sci., 122, p.1614 (2011). http://dx.doi.org/10.1002/app.33882

23. Sanchez, E. M. S.; Cavani, C. S.; Leal, C. V. \& Sanchez, C. G. - Polímeros, 20, p.194 (2010). http://dx.doi.org/10.1590/ S0104-14282010005000034
24. Martin, A. R.; Martins, M. A.; Silva, O. R. R. F. da \& Mattoso, L. H. C. - Thermochim. Acta, 506, p.14 (2010). http://dx.doi.org/10.1016/j.tca.2010.04.008

25. Yang, H. P.; Yan, R.; Chen, H. P.; Lee, D. H. \& Zheng, C. G. - Fuel, 86, p.1781 (2007). http://dx.doi.org/10.1016/j. fuel.2006.12.013

26. De Rosa, I. M.; Kenny, J. M.; Puglia, D.; Santulli, C. \& Sarasini, F. - Compos. Sci. Technol., 70, p.116 (2010). http://dx.doi.org/10.1016/j.compscitech.2009.09.013

27. Muensri, P.; Kunanopparat, T.; Menut, P. \& Siriwattanayotin, S. - Compos. Part A-Appl. S., 42, p.173 (2011).

28. D’Almeida, J. R. M.; Aquino, R. C. M. P. \& Monteiro, S. N. - Compos. Part A-Appl. S., 37, p.1473 (2006).

29. Taha, I.; Steuernagel, L. \& Ziegmann, G. - Compos. Interface., 14, p.669 (2007). http://dx.doi. org/10.1163/156855407782106528

30. Cho, D.; Lee, H. S. \& Han, S. O. - Compos. Interface., 16, p.711 (2009). http://dx.doi.org/10.1163/09276440 9X12477427307537

Received: Oct. 7, 2013 Revised: Mar. 20, 2014 Accepted: Apr. 17, 2014 